\title{
PSIKOEDUKASI STRATEGI MENGELOLA KELAS BAGI GURU DI SEKOLAH DASAR
}

\author{
Rahmah Hastuti ${ }^{1}$ dan Riana Sahrani ${ }^{2}$ \\ ${ }^{1}$ Fakultas Psikologi, Universitas Tarumanagara Jakarta \\ Email:rahmahh@fpsi.untar.ac.id \\ ${ }^{2}$ Fakultas Psikologi, Universitas Tarumanagara Jakarta \\ Email:rianas@fpsi.untar.ac.id
}

\begin{abstract}
ABSTRAK
Teachers need information to understand the characteristics of students, especially in the meanings of individual differences. Community service is intended to answer the problems perceived by the teacher. Based on the information obtained, then formulated the core problems experienced by teachers in the form of the need for knowledge and understanding the characteristics of students of public primary schools in Jakarta. Teachers need information about classroom managing techniques. The aimed of this activity was to improve the knowledge and understanding of teachers through psychoeducation with providing life skills intervention. The subjects or participants in this activity are teachers. A pre-test was first conducted that measured teachers' perceptions of how to manage the class by using Teacher's Sense of Efficacy Scale (TSES) questionnaire. After that, the resource person provides material on classroom management. Data analysis was using SPSS 18 version for windows. The paired sample T-test technique was used to see the effectiveness of the psychoeducation. There was no difference between a score of the pre-test $(M=4.0190, S D=0.51470)$ and a score on the post-test $(M=4.1238, S D=$ $0.52867) ; Z=-0.788$, and $p=0.431>0.05$. However, in the reflection of the activities of each participant expressed the usefulness of this event. Based on the activities that have been done, it can be concluded that the teachers who have provided feedback through self-report evaluation results, states that the students get the benefits of these activities.
\end{abstract}

Kata Kunci: classroom management, Teacher's Sense of Efficacy Scale, teacher

\section{PENDAHULUAN}

Para guru membutuhkan pengayaan informasi guna memahami karakteristik siswa secara umum, perbedaan individual dan makna perbedaan individu. Para peserta memahami mengenai teknik mengelola kelas. Dalam jangka waktu beberapa tahun ke depan, jika dipraktikkan, sekolah akan memiliki model pengelolaan kelas yang baru ataupun memodifikasi model pengelolaan kelas yang telah diterapkan sebelumnya.

Guru di sekolah mitra mengeluhkan beragam hal di antaranya mengenai cara mengelola kelas. Guru mengamati bahwa cukup banyak siswa yang nampak tidak termotivasi dalam belajar. Guru mengakui bahwa tidak selamanya kegiatan akademik di sekolah berjalan sesuai harapan. Siswa yang rajin dan tekun juga tidak dipungkiri jumlahnya sangat sedikit. Prestasi siswa di sekolah yang berlokasi tidak jauh dari area pasar tersebut dinilai oleh guru berpengaruh terhadap perkembangan akademik siswa. Ada banyak bentuk intervensi yang dapat digunakan dalam dunia psikologi, baik itu intervensi individual, kelompok, bahkan komunitas. Pada dasarnya setiap intervensi memiliki pendekatannya masing-masing. Salah satu intervensi yang dapat digunakan dalam berbagai setting dan dapat diterapkan secara individual ataupun kelompok adalah psikoedukasi.

\section{TUJUAN DAN MANFAAT KEGIATAN}

Pelaksanaan PKM dilakukan dalam bentuk psikoedukasi secara interaktif dan dialogis agar dapat diperoleh gambaran umum mengenai pengelolaan kelas oleh guru. Pelaksanaan kegiatan 
ini dilakukan secara interaktif dan dialogis agar dapat diperoleh gambaran umum mengenai persepsi guru mengenai pengelolaan kelas. Pelaksanaan kegiatan dilaksanakan di ruang laboratorium yang di dalamnya terdapat LCD proyektor. Secara umum kegiatan ini menggunakan metode ceramah dalam upaya identifikasi gambaran atau persepsi guru sebagai peserta abdimas.

\section{TINJAUAN PUSTAKA}

Pengertian psikoedukasi yaitu suatu intervensi yang dapat dilakukan pada individu, keluarga, dan kelompok yang fokus pada mendidik partisipannya mengenai tantangan signifikan dalam hidup, membantu partisipan mengembangkan sumber-sumber dukungan dan dukungan sosial dalam menghadapi tantangan tersebut, dan mengembangkan keterampilan coping untuk menghadapi tantangan tersebut. Psikoedukasi adalah treatment yang diberikan secara profesional mengintegrasikan intervensi psikoterapeutik dan edukasi (Lukens \& McFarlane, 2004).

Manajemen kelas yang efektif akan memaksimalkan kesempatan pembelajaran siswa (Charles; Everstson, Emmer, \& Worsham dikutip dalam Santrock, 2011). Para pakar dalam bidang manajemen kelas melaporkan bahwa ada perubahan dalam pemikiran mengenai cara terbaik untuk mengelola kelas. Pandangan lama menekankan pada penciptaan dan pengaplikasian aturan untuk mengontrol tingkah laku siswa. Pandangan baru lebih memfokuskan pada kebutuhan siswa untuk mengembangkan hubungan dan kesempatan untuk menata diri. Berikutnya, pengertian dari teachers' sense of efficacy, yaitu keyakinan guru terkait dengan kemampuan mengelola kelas sehingga tercipta lingkungan kelas yang positif (Tschannen-Moran, Woolfolk-Hoy, \& Hoy, dikutip dalam Fives \& Buehl, 2010). Lebih lanjut bahwa pengukuran terhadap hal ini merupakan isu yang berkembang luas, dan ).diawali dari kajian dari perspektif locus of control (Rotter dikutip dalam Fives \& Buehl, 2010), dan self-efficacy (Bandura dikutip dalam Fives \& Buehl, 2010). Secara konseptual, teachers' sense of efficacy menjadi alat untuk melakukan asesmen ataupun penilaian terhadap beragam populasi.

\section{METODE}

Permasalahan yang dihadapi oleh guru tentunya beragam. Bahkan, tidak hanya dalam area akademis, tetapi juga dalam hal mengelola kelas (Zuriyani, 2015). Manajemen kelas yang mengorientasikan siswa pada sikap pasif dan patuh pada aturan ketat dapat melemahkan keterlibatan siswa dalam pembelajaran aktif. Trend baru dalam manajemen kelas lebih menekankan pada pembimbingan siswa untuk lebih mau mengembangkan perilaku disiplin terhadap dirinya. Dalam trend yang lebih menekankan pada pelajar, guru lebih dianggap sebagai pemandu, koordinator dan fasilitator. Model manajemen kelas yang baru menekankan pada perhatian dan regulasi diri siswa, akan tetapi bukan berarti guru tidak bertanggung jawab atas hal-hal yang terjadi di kelas (Santrock, 2011).

Setelah mendapatkan gambaran lingkungan sekolah yang lebih detail, kemudian inventori yang pertama diberikan kepada peserta. Peserta mengisi kuesioner. Instrumen yang digunakan yaitu Teacher's Sense of Efficacy Scale (TSES) yang disusun oleh Megan Tschannen-Moran dan Anita Woolfolk Hoy pada tahun 2001 (dikutip dalam Dicke et al., 2014). Berdasarkan kajian literatur bahwa teacher's senses of efficacy didefinisikan sebagai keyakinan guru dalam kemampuannya untuk mengatur dan melaksanakan tindakan yang diperlukan untuk membawa hasil yang diinginkan (Five \& Buehl, 2010). Struktur faktor dari alat ukur teacher's senses of efficacy memiliki sejarah yang kaya dan beragam 
yang dimulai pada akhir 1970-an (Tschannen-Moran \& Woolfolk-Hoy dikutip dalam Five \& Buehl, 2010). Kuesioner yang digunakan yaitu versi short form dengan menyertakan 8 butir pertanyaan. Skala ukur berupa Likert, terdiri dari lima pilihan jawaban. Setelah terkumpul semua jawaban maka dilakukan analisis data (skor rerata) respon partisipan. Metode ceramah mengenai teknik mengelola kelas. Peserta diberikan pengenalan mengenai karakteristik siswa. Secara umum kegiatan ini menggunakan metode ceramah dalam mengidentifikasi pengelolaan kelas serta penggunaan self-report dalam bentuk skala psikologi.

\section{PEMBAHASAN HASIL KEGIATAN PKM}

Terkait dengan gambaran data demografis partisipan PKM, berdasarkan jenis kelamin peserta dalam kegiatan pengabdian kepada masyarakat (abdimas) lebih banyak perempuan daripada laki-laki. Secara ringkas dapat dilihat pada tabel 1 berikut ini.

Tabel 1. Gambaran Partisipan PKM Berdasarkan Jenis Kelamin

\begin{tabular}{clrr}
\hline No & \multicolumn{1}{c}{ Jenis Kelamin } & Jumlah & \multicolumn{2}{c}{ Persentase } \\
\hline 1 & Laki-laki & 5 & 33,3 \\
\hline 2 & Perempuan & 10 & 66,7 \\
\hline & Total & 15 & 100,0 \\
\hline
\end{tabular}

Di dalam kegiatan PKM atau abdimas ini, peserta mengisi kuesioner yaitu TSES yang khusus mengenai subdimensi pengelolaan kelas terdiri dari 8 butir. Skala ini dirancang untuk mengetahui mengenai kesulitan yang dialami oleh guru selama di sekolah khususnya dalam pengelolaan kelas dan permasalahan sehari-hari. Berikut hasil pengujian reliabilitas awal dan akhir yang secara ringkas dapat dilihat pada tabel berikut ini.

Tabel 2. Hasil Uji Reliabilitas Awal dan Akhir saat Pre-test dan Post-test

\begin{tabular}{llll}
\hline \multicolumn{2}{l}{ Reliabilitas Awal } & \multicolumn{2}{l}{ Reliabilitas Akhir } \\
\hline Pre-Test & Post-Test & Pre-Test & Post-Test \\
0,814 & 0,832 & 0,793 & 0,833 \\
\hline
\end{tabular}

Berikut adalah hasil pengujian normalitas data untuk mengetahui lebih lanjut analisis data selanjutnya menggunakan nonparametrik karena berdasarkan pengolahan data bahwa data tergolong tidak normal. Berikut ini tabel yang menyajikan informasi hasil uji normalitas data.

\begin{tabular}{ll}
\multicolumn{2}{c}{ Tabel 3. Hasil Uji Normalitas } \\
\hline \multicolumn{2}{l}{ Hasil Uji Normalitas } \\
\hline Pre-Test & Post-Test \\
\hline 0,200 & 0,002 \\
\hline Tidak Normal & Tidak Normal \\
\hline
\end{tabular}

Setelah pada awalnya terlebih dahulu dilakukan uji normalitas data, kemudian dilakukan pengujian normalitas data yang dilakukan untuk menentukan teknik analisis yang digunakan yaitu dengan Paired Sample T-Test untuk sebaran data normal atau Uji Wilcoxon untuk sebaran data tidak normal.

Tabel 4. Perbandingan Hasil Pre-Test dan Post-Test

\begin{tabular}{ll}
\hline $\mathrm{Z}$ & Asym (2-tailed) \\
\hline$-0,788$ & 0,431 \\
\hline
\end{tabular}


Berdasarkan hasil pengolahan data bahwa tidak ada perbedaan skor antara pre-test $(\mathrm{M}=$ $4,0190, \mathrm{SD}=0,51470)$ dengan skor pada post-test $(\mathrm{M}=4,1238, \mathrm{SD}=0,52867) ; \mathrm{Z}=-$ 0,788 , dan $\mathrm{p}=0,431>0,05$. Persepsi guru terkait pengelolaan kelas tidak mengalami perubahan sebelum dan sesudah kegiatan psikoedukasi.

Tabel 5. Gambaran Refleksi atas Kegiatan Psikoedukasi

\begin{tabular}{|c|c|c|}
\hline No & Kesan & Frekuensi \\
\hline 1 & $\begin{array}{l}\text { Diskusinya amat sangat bermanfaat sekali buat } \\
\text { saya. Harapan saya pertemuan ini tidak hanya } \\
\text { cukup sampai saat ini saja. }\end{array}$ & 1 \\
\hline 2 & $\begin{array}{l}\text { Kesan saya agar dilanjutkan untuk para wali } \\
\text { murid. }\end{array}$ & 1 \\
\hline 3 & $\begin{array}{l}\text { Lewat pertemuan ini kita semakin bergiat } \\
\text { melaksanakan tugas dalam mengajar dan } \\
\text { belajar, khususnya saya. }\end{array}$ & 1 \\
\hline 4 & $\begin{array}{l}\text { Menyenangkan pertemuan hari ini. Perlu } \\
\text { diadakan lagi penyuluhan yang melibatkan } \\
\text { orangtua murid. }\end{array}$ & 1 \\
\hline 5 & $\begin{array}{l}\text { Menyenangkan pertemuan ini, menambah } \\
\text { wawasan dan dapat menemukan solusi yang } \\
\text { sehari-hari kita alami }\end{array}$ & 1 \\
\hline 6 & $\begin{array}{l}\text { Perlu untuk mengadakan pertemuan antara } \\
\text { guru dan orangtua }\end{array}$ & 1 \\
\hline 7 & $\begin{array}{l}\text { Pertemuan ini cukup menarik, dapat berbagi } \\
\text { informasi pengelolaan kelas dan dapat } \\
\text { mewujudkan cita-cita anak didik. }\end{array}$ & 1 \\
\hline 8 & $\begin{array}{l}\text { Sebaiknya diadakan sesi khusus untuk } \\
\text { parenting, agar seimbang antara pendidikan } \\
\text { sekolah dan pendidikan rumah, kalau bisa } \\
\text { fokuskan pada orangtua yang anaknya } \\
\text { bermasalah dari segi akademik atau moral. }\end{array}$ & 1 \\
\hline 9 & Sudah baik. & 7 \\
\hline Jumlah & & 15 \\
\hline
\end{tabular}

\section{Gambaran Jalannya Kegiatan Analisis Kebermanfaatan Metode Ceramah}

Oleh karena sesi psikoedukasi hanya berupa ceramah sehingga hanya mengena pada aspek kognitif serta afeksi dan belum merubah perilaku. Dapat disimpulkan bahwa dari kegiatan ceramah yang dilakukan pada guru, feedback yang diberikan melalui hasil evaluasi pasca pelaksanaan ceramah memiliki kesan yang positif, peserta mendapatkan manfaat dari kegiatan tersebut. Walaupun dari harsil pengolahan data secara statistik, tidak ada pengaruh pemberian psikoedukasi untuk meningkatkan pengetahuan dan pemahaman peserta terkait dengan pengeloaan kelas. 


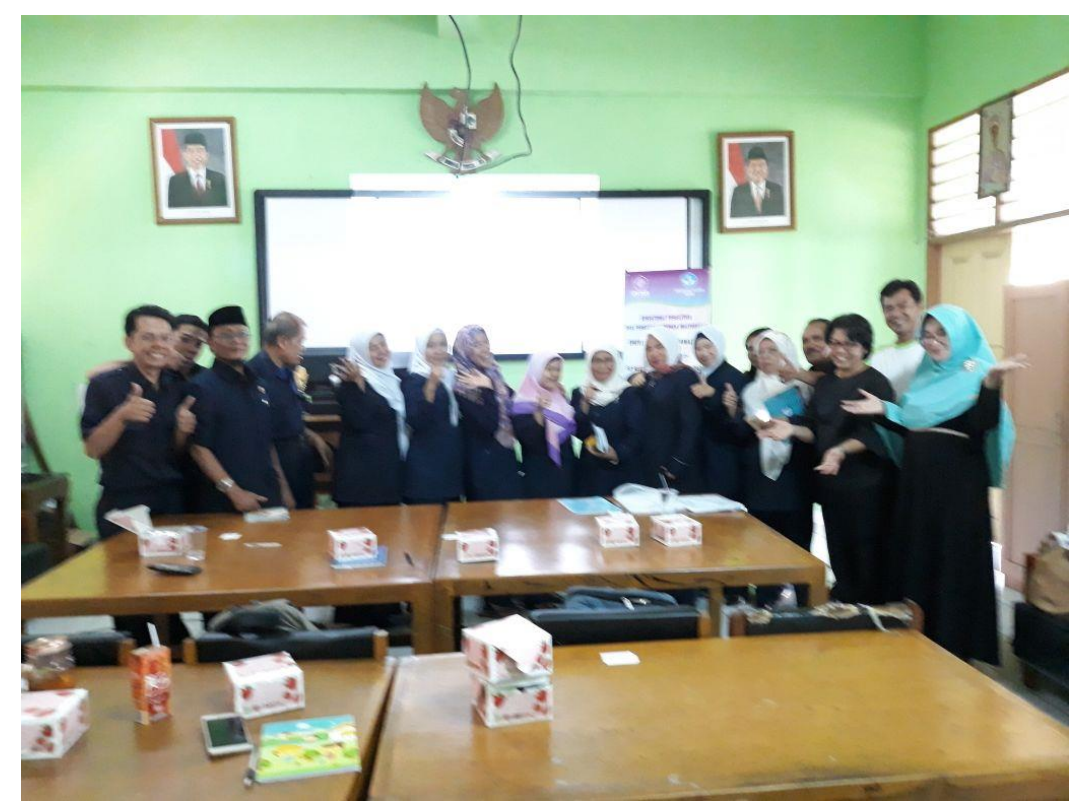

Gambar 1. Situasi kegiatan PKM

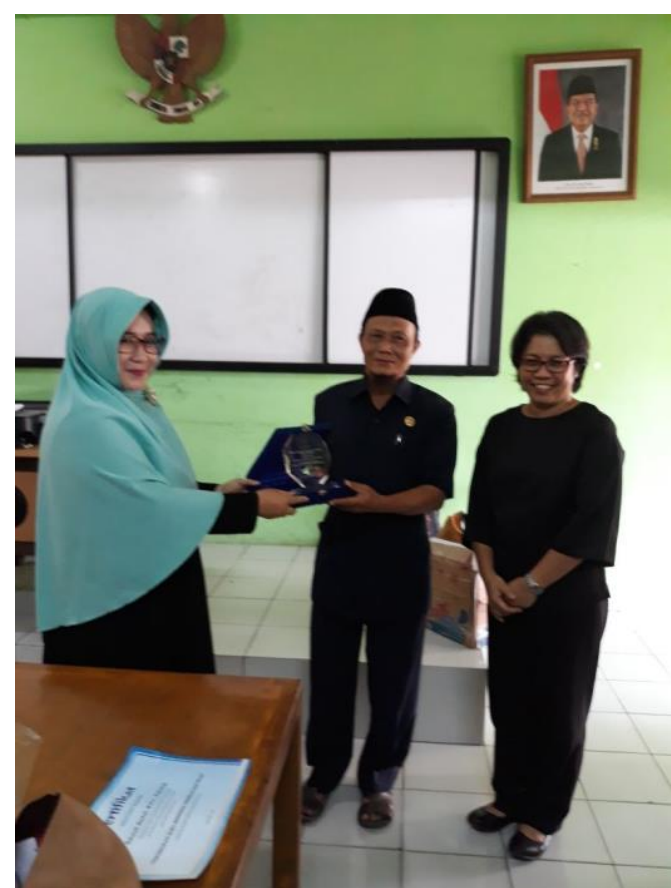

Gambar 2. Penyerahan plakat kepada instansi mitra.

\section{KESIMPULAN DAN SARAN}

Tidak ditemukan perbedaan skor pada pre-test $(\mathrm{M}=4,0190, \mathrm{SD}=0,51470)$ dengan skor pada post-test $(\mathrm{M}=4,1238, \mathrm{SD}=0,52867) ; \mathrm{Z}=-0,788$, dan $\mathrm{p}=0,431>0,05$. Namun demikian, pada hasil refleksi kegiatan setiap peserta menyatakan kebermanfaatan kegiatan pengabdian masyarakat dalam bentuk ceramah ini. Berdasarkan kegiatan yang telah dilakukan, dapat disimpulkan bahwa para guru yang telah memberikan feedback melalui hasil evaluasi selfreport, menyatakan bahwa siswa-siswi mendapatkan manfaat dari kegiatan tersebut.

Seperti yang terlihat dari hasil psikoedukasi dalam laporan abdimas ini, ada beragam metode untuk menilai persepsi, masing-masing dengan kekuatan dan keterbatasan dan berguna untuk tertentu tujuan. Bahkan, berdasarkan hasul survei berupa self-report, nampak ada variasi dalam 
persepsi terkait pengelolaan kelas pada para guru di sekolah dasar negeri. Pada umumnya, abdimas ini dapat menjadi saluran untuk membagikan informasi untuk meningkatkan wawasan pengetahuan, khususnya bagi setiap pihak yang memerlukan.

Melalui kegiatan abdimas dalam bentuk psikoedukasi kepada guru diharapkan menjadi bekal yang bermanfaat bagi para pada khususnya serta untuk institusi sekolah pada umumnya. Bagi guru dapat menumbuhkan insight dalam kegiatan pendidikan dan pengajaran sehingga dapat dilaksanakan dengan baik. Melalui jalinan kemitraan antara perguruan tinggi dan pihak sekolah, maka terbina komunikasi dan kerjasama yang baik sehingga diharapkan mampu menjadi simbiosis mutualisme atau kerjasama yang saling menguntungkan bagi kedua belah pihak. Guru yang dalam keseharian mendapat beragam permasalahan dala mengajar, tentunya mendapatkan hal baru berupa wawasan pengetahuan ataupun knowledge sharing sehingga dapat memahami bahwa value pendidikan dan pengajaran anak didik merupakan aspek yang paling utama dalam pendidikan di sekolah.

\section{Ucapan Terima Kasih (Acknowledgement)}

Tim abdimas yang merupakan dosen tetap di F.Psikologi UNTAR, menyampaikan terima kasih kepada segenap Pimpinan Yayasan Tarumanagara, Rektor Universitas Tarumnagara serta jajarannya, Bapak Jap Tji Beng, Ph.D selaku Direktur Direktorat Penelitian dan Pengabdian kepada Masyarakat Universitas Tarumanagara serta segenap stafnya serta pimpinan Fakultas Psikologi Universitas Tarumanagara atas fasilitasinya. Selain itu, kami berterima kasih kepada institusi mitra selaku instansi pemberi data yaitu Sekolah Dasar Negeri X di Jakarta Barat, Jakarta, juga kepada asisten pelaksana PKM, serta berbagai pihak yang tidak dapat disebutkan satu persatu.

\section{REFERENSI}

Akin-Little, A., Little, S.G., Bray, M.A., \& Kehle, T.J. (2009). Behavioral intervention in school: Evidence-based positive strategies. Washington, DC: American Psychological Association.

Dicke, T., Parker, P. D., Marsch, H. W., Kunter, M., Schmek, A., \& Leutner, D. (2014). Self-efficacy in classroom management, classroom disturbance, and emotional exhaustion: A moderated mediation analysis of teacher candidates. Journal of Educational Psychology, 106(12), 569-583. Retrieved from http://dx.doi.org/10.1037/a0035504

Fives, H. \& Buehl, M. M. (2010). Examining the factor structure of the teachers' sense of efficacy scale. The Journal of Experimental Education, 78, 118-134. doi: 10.1080/00220970903224461

Lukens, E. P. McFarlane, W. R. (2004). Psychoeducation as evidence-based practice: Consideration for practice, research, and policy. Journal Brief Treatment and Crisis Intervention, 4. Oxford University Press.

Santrock, J. W. (2011). Educational psychology (5 ${ }^{\text {th }}$ ed.). New York, NY: McGraw Hill.

Zuriyani. E. (2015). Kementrian agama: Peranan guru dalam pengelolaan kelas efektif. Diunduh dari https://www.youtube.com/watch?v=T62hcSw6LCg

Five, H., \& Buehl, M.M. (2010). Examining the factor structure of the teachers' sense of efficacy scale. The Journal of Experimental Education, 78, 118-134. doi: 10.1080/00220970903224461 